\title{
A FOUR YEARS FOLLOWING FOR OPEN LEARNING IN A NUMERICAL METHODS COURSE BASED ON LEARNING ANALYTICS
}

\author{
Francisco Javier Delgado-Cepeda \\ Tecnologico de Monterrey, campus Estado de Mexico \\ Carretera a Lago de Guadalupe km. 3.5, Atizapán, Estado de Mexico, Mexico. CP. 52926
}

\begin{abstract}
Numerical methods education has become technologically developed with the computer diversification. Subsequently, the mobile technologies have empowered more versatile media than reading in education to strengthen specific learning. The emergence of hybrid learning has raised new ways to approach education: screencasting, e-books, codes, online tests, etc. This article presents the follow-up of an open resource for numerical methods courses despite expressly designed for a captive enrolled audience within a university, it remains open for external users. The current analysis is built departing from learning analytics embedded in the site, discriminating only the behaviour of informal (non-enrolled) users.
\end{abstract}

\section{KEYWORDS}

Open Education, Blended Learning, Learning Analytics, Screencasting

\section{INTRODUCTION}

Professional development of numerical methods in science and engineering (as well disciplines requiring estimation or simulation) has become highly professionalized since computer revolution (Black, 2014). Education in this field has changed huge from theoretical courses of numerical analysis into computer methods (Delgado, 2013). The author has worked in this issue by 15 years introducing the use of computer into the classroom. There, repositories of educative electronic materials born departing from publication of simple computational codes until the use of tools, technologies and more specific learning media in the course (learning and evaluation), which were feasible with the mobile revolution (Siemens, 2005), where the development of educative applications continues growing closer to the needs of teachers and students.

An experience reported previously (Delgado, 2016; 2017), presented those materials originally intended for a captive audience in the formal courses on an open platform (Weebly). The course's site was recognized by the Reimagine Education Initiative in 2016 as a Shortlisted Project and it won two innovation grants (NOVUS 2015 and 2016). When such materials were published for the general public, the outcomes and reception were amazing: in only one semester the related videos posted on You Tube exceeded one hundred thousand visits. Today, those materials continue improving, they are available for any visitor to the site.

Collected data in the form of analytics provide a lot of information about the behaviour of the users. Learning Analytics term (Picciano, 2012; Wong, 2017) was coined to define the process of measurement, collection, analysis and reporting of data obtained during a process of learning and its relationship with users and their behaviour (Greller and Drachsler, 2012). In online learning, it refers to a series of indicators about the users operation through the learning process. Typically, the purpose of learning analytics is to use this information in the understanding of the process to seek optimize it, by including a growing number of indicators inferred from an internet connection (Wong, 2017).

The aim of this article is to present the impact of the numerical methods course in terms of utility, accessibility, outreach and recruitment of informal students as open resource from the perspective of learning analytics. The analysis presented should give some insight about the plausible value of the related educative resources for a non-enrolled audience or more ambitiously for open Education. Section 2 establishes the objectives of the research and its scope in terms of available data on the use of resources. Section 3 matches such objectives with the analytics available as research method presenting structured and measurable outcomes together with their discussion. Finally, the conclusions are set out in the last section. 


\section{OPEN ACCESS NUMERICAL METHODS COURSE' SITE AND RESEARCH SCOPE}

The course of numerical methods originally based on Blackboard was clearly aimed for local university users. There, a daily syllabus guided to the students through Power Point presentations, downloadable basic codes, online assessments, a delivery repository and feedback of tasks (Delgado, 2013). When it was transferred to Weebly in an open resource format, a very wide diversity and a growing collaboration in terms of embedded applications could supplement the Blackboard performance and they were constituted in learning materials both for formally enrolled students as well for informal users around the world. The decision to open the educational resources allowed to support learning of a large number of users on the site, strengthening STEM initiatives (Siemens, 2005; Delgado, 2016). The formal course for enrolled students has a structure involving dissemination, theoretical aspects, programming, extra-class activities, e-book, feedback and evaluation. For non- enrolled students all these sections are open except the last two.

The advent of collaboration tools was increasing in the course (Delgado, 2016b): online evaluation tools, feedback and repositories conforming the site since 2013 have been enriched over time by adding associated dissemination materials, learning projects, and an e-book. Despite, there was a series of generic videos covering the management of the programming for the major themes in the course on a YouTube channel associated with it. In 2014, a segment of screencasting was included covering $100 \%$ of the programming learning component. The learning analytics based on access and times of usage began in 2014 through Weebly analytics and then complemented with Google analytics.

\subsection{Learning Analytics in the Course's Site}

Analytics split in two groups the analysis for the learning impact for the enrolled students and another for the non-enrolled ones. An analysis for the first group was reported in Delgado (2017). In parallel, due to the impact on the access for non-enrolled users, it would be important to analyse related aspects for this group. Despite no follow-up exists in relation to the performance, the possibility to improve the open education experience could be available regarding demographics data and some usage analytics there. In addition to learning analytics in Google and You Tube, an invitation to answer a usage survey (discriminated by each user group between enrolled and non-enrolled). Thus, the present analysis is built from the impact for the non-enrolled group based on this set of demographic indicators, analytics and the survey outcomes.

Google analytics and Weebly analytics are tools to gather information about the way each user navigates within the site interacting with different content. Data can be identified by user statistics (IP address or through a previous registration process). Google analytics is a tool to collect information and interaction with the user, even after visiting the site or based on practices developed in. It only requires the inclusion of a code on the site to account for its use. Figure 1 shows a generic dashboard of some statistics being tracked: country, city, date, time of connection and its features (browser, computer, etc.).
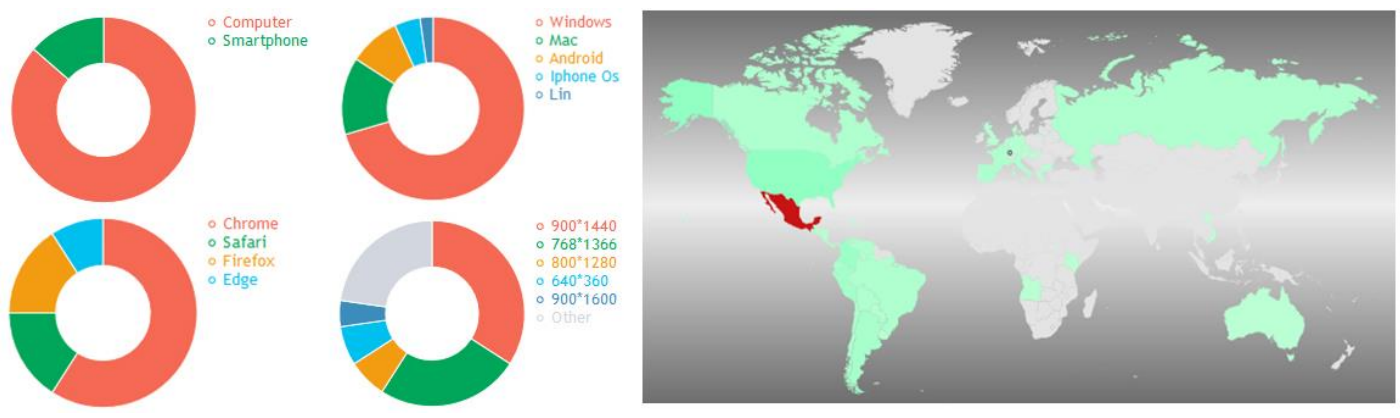

Figure 1. General dashboard for the course's site demographics analytics: origin of the access, operative system, navigator and screen resolution for the adaptive view, together with the general world access map 


\subsection{Research Objectives in the Current Report}

This report uses the analytics embedded in the site looking for the impact on those not-enrolled users. The research objectives of this report has been set as: a) to set a structure for the analytics in demographic terms and usage level, and b) to deduct from such analytical learning behaviours an assigned value to those online materials. To establish this analysis, there are demographic indicators as: country and city, age, technological details of access, sequence of pages accessed, time per page, views for each screencast by user, date and time of access, outcomes of screencasting survey, discrimination between visit and visitor, etc. This pair of goals seek to establish more binding relations between users and the site.

Figure 2 shows a synthetic map of the available analytics within the site and its associated You Tube channel. The analytics allow to identify the demographics of users (even if they are or not enrolled) in terms of age, origin and whether it is even a repetitive visitor (discrimination is made from the IP address). It is also possible to track the date, duration of visit by page and terminal page by visit when the user makes a specific search within the site. It is also possible to make a similar follow-up by accessing the screencasting area, then determining if it is a shortcut to the corresponding You Tube channel. If the access is made through the course, users can perform a brief evaluation for the screencasting section, discriminating if they used it repeatedly or not within their respective learning activities. A good number of participants have given their evaluation through this quick survey. Through these demographics and learning analytics, a method and a criterion have been established to assess the interest on learning objectives. A remarkable aspect is that $95 \%$ of users are between 17 and 24 years old.

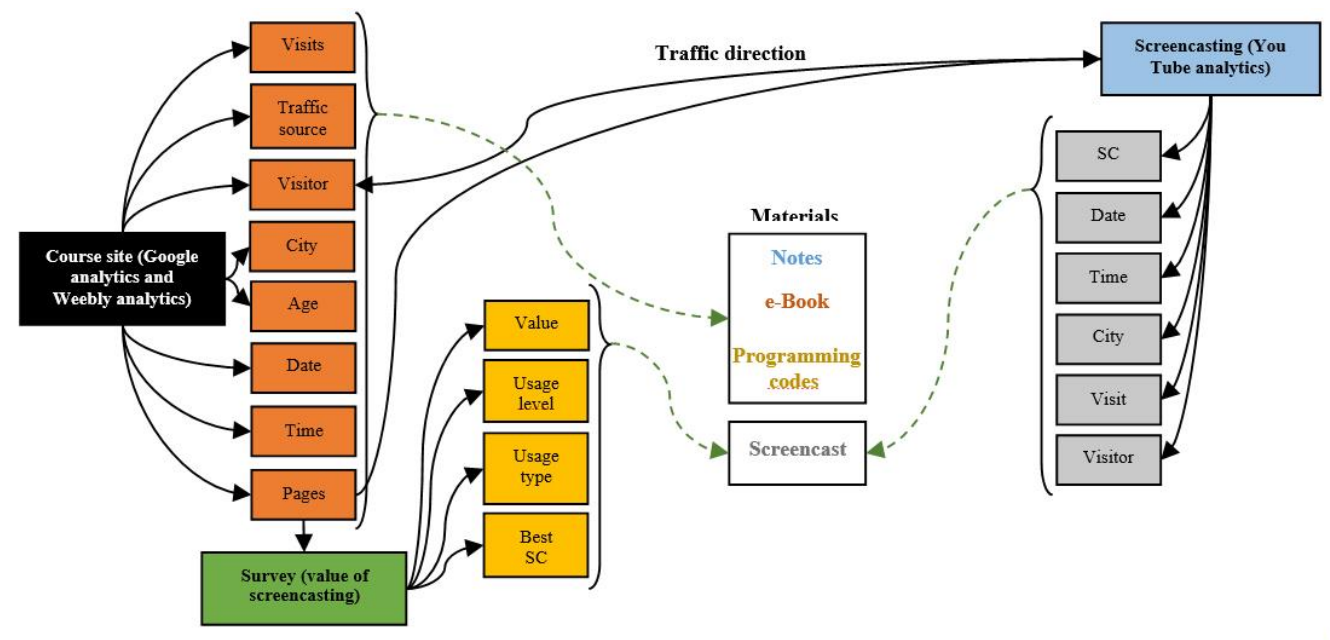

Figure 2. Most representative analytics incrusted in the course's site and in the related You Tube cannel

\section{RESEARCH METHOD, OUTCOMESAND DISCUSSION}

This section provides the description of the method to infer additional information from the available analytics. We describe the type of informal users using the course through direct statistics. Table 1 collects the indicators referred in Figure 2 being used into the analysis in the present report (discriminating informal users), as well as their source and associated parameters.

\subsection{Association method for the analytics}

The remaining analysis discriminates non-enrolled students as students having access outside of metropolitan area of Mexico City (even it left out some students within the university in the same course but with other teachers using the site informally). To meet the first objective of research, analytics have been grouped as is depicted in Table 1. The second objective is reflected in the analysis of information collected. 
Table 1. Associated analytics included in the current report

\begin{tabular}{|c|c|c|c|}
\hline Type of analytics & Level & Period & Origin \\
\hline Demographics & $\begin{array}{l}\text { City and country } \\
\text { Date of Access } \\
\text { Visit or visitor }\end{array}$ & 2014-2018 & Course site \\
\hline Usage of materials & $\begin{array}{l}\text { Total time of usage } \\
\text { Pages visited } \\
\text { Terminal page } \\
\text { Effective time by page }\end{array}$ & 2014-2018 & Course site \\
\hline Usage of screencasts & $\begin{array}{l}\text { Total time of usage } \\
\text { Screencasts visited } \\
\text { Terminal screencast } \\
\text { Effective time of view }\end{array}$ & 2016-2018 & You Tube channel \\
\hline Screencasting survey & $\begin{array}{l}\text { Opinion of screencasting } \\
\text { Personal type of usage } \\
\text { Opinion about best screencast }\end{array}$ & 2016-2018 & Course site \\
\hline
\end{tabular}

First, we are interested in the behaviour of the level of access and its implications related to the type of support provided by the site (in particular origin of access and periodicity). Here, the most requested sections have been tracked together with their usage time. We are also interested in some properties of screencasting access by using the combined information from Google and You Tube analytics. In this case, we tracked the origin of access, time displaying each screencast, and discrimination between visit and visitor. Finally, before of conclusions, we will present synthetic outcomes for the screencasting survey in the course.

\subsection{Structured Outcomes from the Analytics}

Figure 3 presents two perspectives of the access for the top ten countries using the course site. Figure 3a presents the access continuously accumulated in the period August 2014-July 2018 (softened in monthly periods) and Figure $3 \mathrm{~b}$ presents the weekly accesses in the same period. The latter denotes the linear character in the cumulative frequency and the semester pattern in the accesses respectively. United States and Russia stand out in relation to the level of use (still other twenty countries on the list continue the minority under those ten) despite they are not Spanish-speaker countries.

For the total accesses concerning Figure 3, Table 2 shows synthetically the distribution of the $98 \%$ of accesses longer than 5 minutes in different sections during August 2014-July 2018 by non-enrolled users. Screencasting section was the most accessed even departing from the site (not counting the shortcuts from the YouTube channel), followed by the section of programming codes and e-book showing a comparable use. By referring exclusively to the screencasts, analysing now the total number of accesses, the shortcuts from You Tube channel represent only $7 \%$ of the access to the site, while from the total accesses to You Tube channel, only $21 \%$ continue to the site after a direct query there.

Table 2. Relative percentage of usage for course sections by informal users

\begin{tabular}{lllc}
\hline Level & Section & Subsection & Percentage \\
\hline 1 & Screencasting (42\%) & Syntax of Mathematica & $13 \%$ \\
& & Non-linear equations & $12 \%$ \\
& & Equation systems & $9 \%$ \\
& & Differential equations & $8 \%$ \\
2 & \multirow{3}{*}{ Programming codes (30\%) } & Equation systems & $9 \%$ \\
& & Non-linear equations & $8 \%$ \\
& & Differential equations & $6 \%$ \\
3 & e-book (23\%) & Derivative and integrals & $7 \%$ \\
& & Non-linear equations & $8 \%$ \\
& & Differential equations & $7 \%$ \\
& & Equation systems & $5 \%$ \\
4 & Proposed projects (2\%) & Derivative and integrals & $3 \%$ \\
& & Proposed projects & $2 \%$ \\
\hline
\end{tabular}


Figure 4 shows different aspects of the access to the screencasts. Figure $4 \mathrm{a}$ is focused on the most popular screencasts and the related access percentage, the graph is presented in logarithmic scale on the radial axis. Although a large number of users looking for an introduction to the syntax of Mathematica, the following two level of accesses (greater than $10 \%$ of the views) and the minors (distributed between $10 \%$ and $0.5 \%$ ) are related to the numerical methods content. The percentage differences between the total number of views and the playing time should be distinguished. Those screencasts references starting with SCX.Y refers to specific content where $\mathrm{X}$ is the course unit and $\mathrm{Y}$ their consecutive number. The remaining screencasts not following this nomenclature are generic videos for every unit. Figure $4 \mathrm{~b}$ shows the geographical distribution of the accesses to the screencasts (visits and visitors in a differentiated way). Also, we report the ratio between visitors to visits $(\mathrm{V} / \mathrm{v})$ in percentage, denoting some countries where the attention is focused on certain very assiduous visitors (United States, Canada, Belgium, Asia-Pacific, Greece, Ireland, Nicaragua and Puerto Rico).
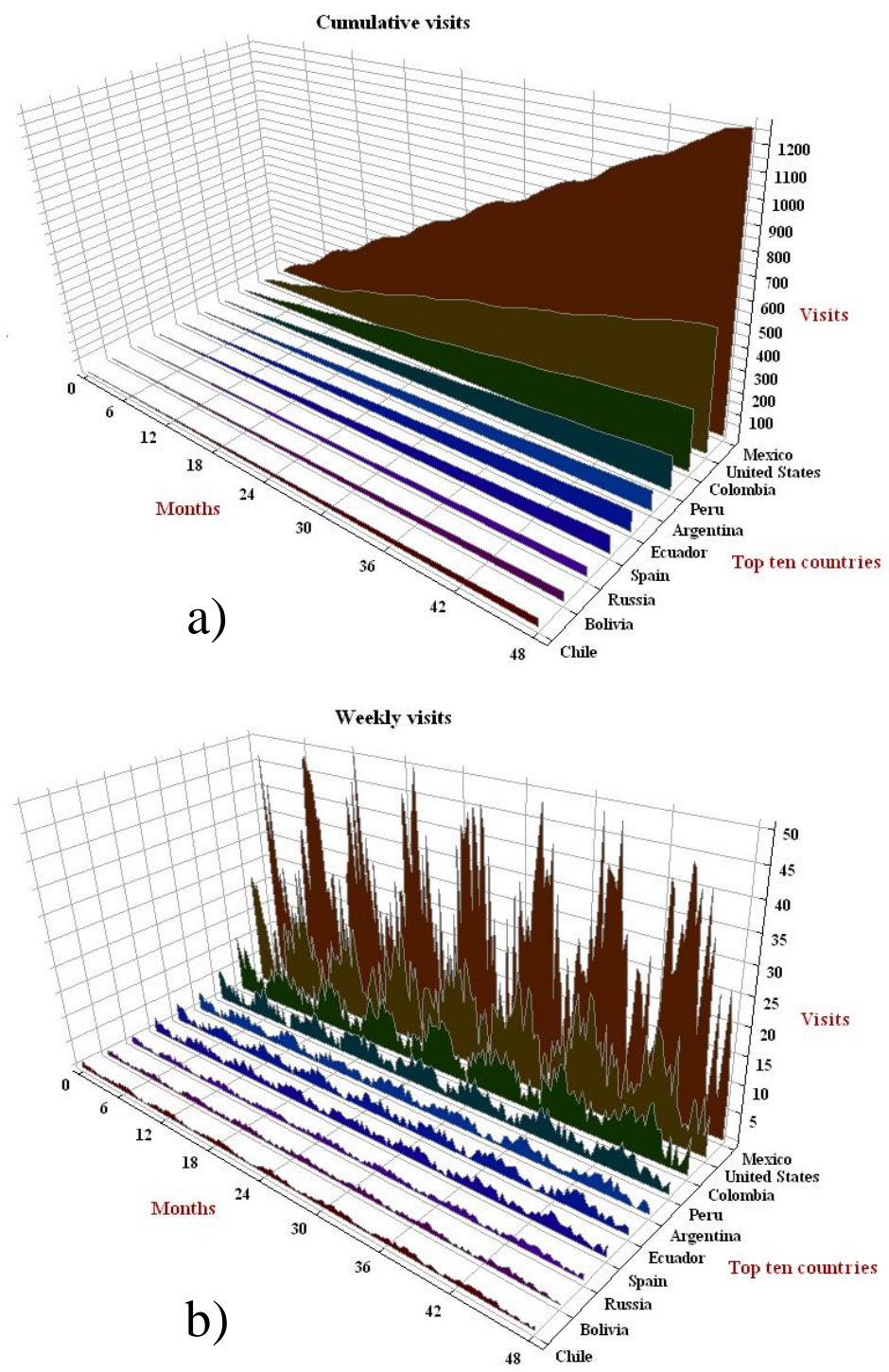

Figure 3. General access statistics for the numerical methods course for the top ten countries in the last two years:

a) accumulative visits smoothed by month depicting a linear grown, and b) weekly visits through such period

Finally, concerning to the evaluation of screencasts, Figure 5 shows the outcomes for each cohort of application in the last three years since 2015. Figure 5a shows the percentage of opinion at every possible level of use: 1) not useful, 2) once weekly, 3) once by evaluation period (approximately one month), and 4) continuously. While not all users respond the survey, it is assumed that those who did it are repetitive 
users of the section and it is clear that they used the screencasting section permanently. Figure $5 \mathrm{~b}$ shows the main reasons for the use of the screencasts, showing that use is regular and it serves both to improve the understanding as well as to scaffold the students' tasks. Finally, Figure 5c shows the opinion about the more valuable screencasts by each cohort, pointing to the syntax of Mathematica, systems of equations and differential equations predominantly. This is consistent with the outcomes of Table 2 and Figure 4a. In the next section we discuss the meaning of the results presented so far.
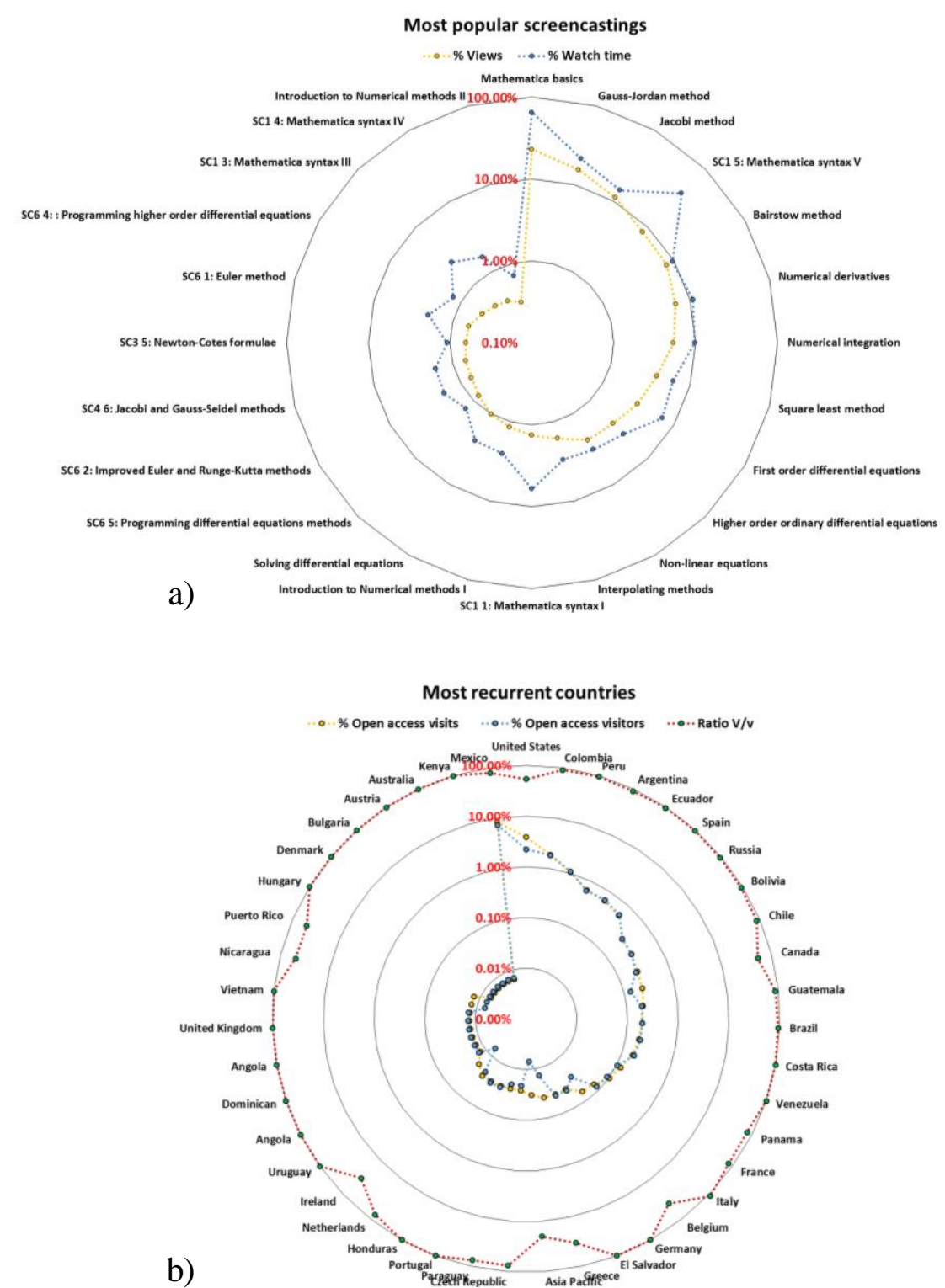

Figure 4. You Tube access in last three years: a) views and watch time normalized, and b) visits and visitors by country

\section{CONCLUSIONS}

Departing from the demographic and learning analytics collected during the user accesses, the international impact of numerical methods course is remarkable. The depicted analytics have allowed to know the breadth of the users as well as their primary interests related with the diversity materials presented in the course. Of particular interest has been clearly the screencasting section. Most of the users are college or graduate 
students, reflecting an underlying semester behaviour in their usage. Some non-Spanish speaker countries are located in the first places, although it would be convenient to discriminate whether or not these users are Spanish-speakers. Along with the screencasting, the programming code section has widely appealed by the users. The higher level of access involves numerical methods considering a distributed programming in subroutines, due to the complexity of such methods (Equations systems and Differential equations).

Regarding the regularity of accesses to the screencasting section, it emphasizes in general (with the exception of some countries) most of the users can be casual looking for concrete materials (due to the parity between the number of visits and visitors in the most cases). On the other hand, in contrast with the formal users (Delgado, 2017), informal users seek generic themes presentations, instead of those screencasts with specific content (those with SCX.Y nomenclature in Figure 4). Because users fulfilling the opinion survey are likely users with recurrent visits (within the informal users group), it is understandable their opinions become closer to those given by formal users (Figure 5a-b). In any case, the outcomes in Figure 5b shows certain fidelity from certain sector of such users.

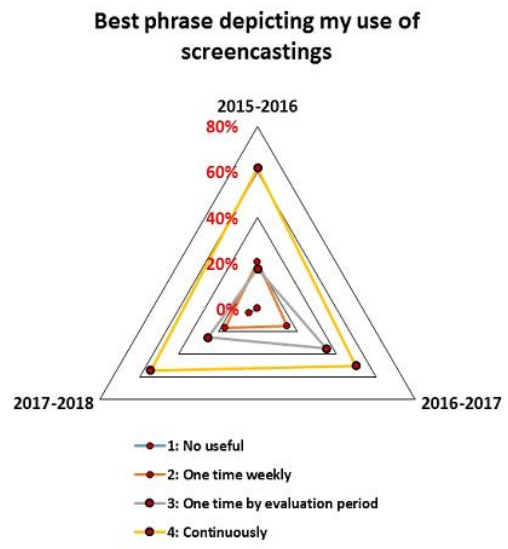

a)

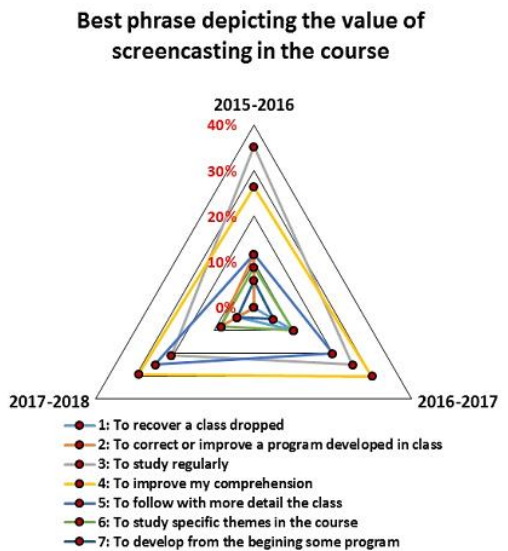

b)

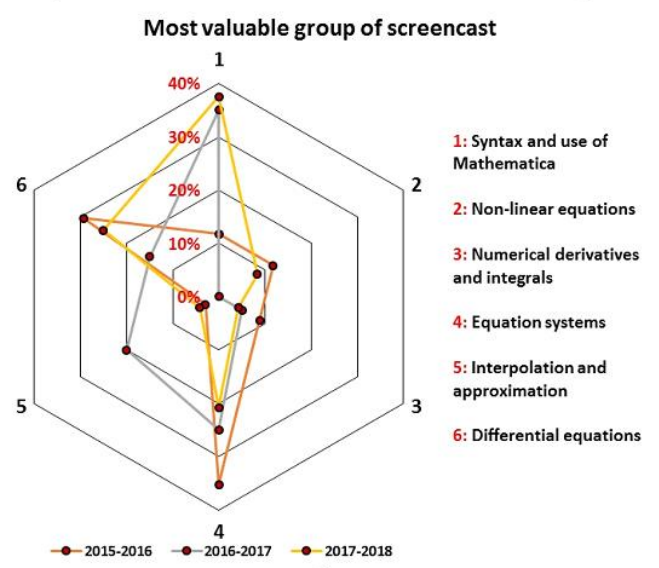

c)

Figure 5. Synthetic outcomes in the opinion survey about screencasting for each cohort: a) general opinion,

b) main use declared for the screencasts, and c) opinion about the most useful group of screencasts

Thus, regarding inferences about the visitors in the current research in order to give a more valuable experience in the course site, a detailed following of some interested non-enrolled students is in order. It could be achieved by stating an optional registration of users in the site, not for restrict the access to it but instead to provide a closer contact about certain necessities around of their learning. Despite, it requires time and resources, which should be analysed in terms of feasibility, nevertheless it could be still considered in an automated form. This aspect should be considered as future work in terms of offering a more individual following to some users using continuously the educative materials as research objective. The present study should be extended to include other available analytics and more direct measurements for the impact on the subset of users under registration. 


\section{ACKNOWLEDGEMENT}

Authors would like to acknowledge the financial support of Novus Grant with PEP no. PHHT023-18ZZ00013, TecLabs, Tecnologico de Monterrey, Mexico, in the production of this work.

\section{REFERENCES}

Black, D. 2014. MOOCs and the Move Toward Competency-Based Education. Retrieved from: http://moocs.com/ index.php/moocs-and-the-move-toward-competency-based-education/

Delgado, F. 2013. A numerical methods course based on b-learning: integrated learning design and follow up. International Journal of Mobile and Blended Learning 5 (1).

Delgado, F. 2016. Upgrading to Numerical Methods Course into New Mobile Technologies for Mathematical Education: An Approach Based on Flexibility and Skill Development. In Mobile and Blended Learning Innovations for Improved Learning Outcomes (David Parsons, ed.). IGI Publishing: London.

Delgado, F. 2017. Small Private Online Research: A proposal for a Numerical Methods course based on Technology use and Blended Learning. Proceedings of Mobile Learning 2017.

Gleeson, T. 2014. Co-Teaching a Blended Class across Universities. Inside Higher Ed. Retrieved from: http://www.insidehighered.com/blogs/higher-ed-beta/co-teaching-blended -class-across-universities

Greller, W. and Drachsler, H. 2012. Translating Learning into Numbers: Toward a Generic Framework for Learning Analytics. Educational Technology and Society. 15 (3), pp. $42-57$.

Picciano, A. 2012. The Evolution of Big Data and Learning Analytics in American Higher Education. Journal of Asynchronous Learning Networks. 16, pp. 9-20.

Siemens, G. 2005. Connectivism: A Learning Theory for the Digital Age. International Journal of Instructional Technology and Distance Learning, vol. 2, no. 1, pp. 3-10.

Wong, T. 2017. Learning analytics in higher education: an analysis of case studies. Asian Association of Open Universities Journal, 12 (1), pp.21-40. 